\title{
7. Citizens, Customers, Clients or Unwilling Clients? Different and effective strategies for citizen-centric delivery
}

\author{
Lynelle Briggs
}

In this chapter I will explore the shift to 'citizen-centred service delivery models' in the Australian Public Service (APS) and touch on some of the associated theories and international developments. In doing so, there are a couple of key questions we need to consider. The first is how are we changing the way we engage with citizens? And secondly, is what we are doing enough? It is also important to consider the key opportunities for, and challenges to, realising truly people-centred services: it is not only necessary to raise the standards of government interactions with the community, but also to radically rethink how some services are designed and delivered.

\section{How are we changing the way we engage with citizens in Australia?}

Let me begin by recounting a little of my own recent experiences with service delivery reform. In doing so, I will touch on some of the main drivers for reform, give an idea of the scope of the structural changes underway in the APS in the service delivery arena and highlight some of the things that have been happening in the human services portfolio to enhance community engagement.

As many readers would know, on 1 July 2011, three great APS institutions - Medicare Australia, Centrelink and the Department of Human Services came together to form one department of state. This milestone creates a new department that will give policy clout to service delivery, with service delivery now being recognised as a valid policy stream in itself. The department is driving a new way of delivering health access services, income support and child support services to the Australian community. That new way is all about:

- merging services so that they are refocussed to deliver better results for people

- having the information and tools to assist Australians in accessing a range of community or other services that might meet their needs 
- Australians feeling that they are able to work with the department to devise new services that better meet their needs, share in the design of those services and advise on the best method of delivery of the services to them

- transforming the department's operations electronically and procedurally to provide the basis for all of this to happen.

The merger is a large operation by anyone's standards: 40,000 staff, 550 offices, 170 programs and services, and contacts with just about every Australian each year. The department is the face of the Australian Government in the community; we have an enormous opportunity to deliver change.

The creation of the new department signals one of the most significant changes for the delivery of social and health payments and related services in Australia since the mid 1990s. It is a direct response to the need to put the people we serve at the centre of our work and build our structures around them.

Today, Australians and New Zealanders expect quality services from government, reliable advice from expert service staff and convenient online access. We expect quick, convenient service for straightforward services like pension or Medicare payments or entitlement adjustments, but we want higher level service that delivers results when we are in need or in trouble.

We expect to be treated like individuals with particular needs, to be treated with respect and courtesy, and to be able to trust the public sector to be there when we need it.

In short, Australians expect to see services delivered in ways that work for them. For this reason we devised the catchphrase 'easy, high quality and work for you' ${ }^{1}$ — our aim for service delivery reform.

To deliver on this bold reform promise is a huge undertaking and people want to know how to do it. In my opinion, it is necessary to:

- move systematically, thoughtfully and respectfully

- make your vision a priority

- align your people and your stakeholders with the vision and ensure that your people desire the reform

- align values; use what is valued as a base, and build on that. In the public service, making people's lives better is always a good place to start because those core values are a strong part of every public servant

- have a plan; we have a large and complex plan with clear lines of accountability and time scales, which is driven from the top. The plan has a

1 This is the catchphrase for service delivery reform throughout the Department of Human Services. 
national roll out so, while we are piloting some elements, we are not shirking the responsibility to drive reform nationally and to deliver nationwide

- fix the blockages. At this stage, that is about integrating our systems and processes and making our online systems easy and intuitive for everyone to use; but it has also been about bringing our managers on board with the changes.

But, perhaps above all, active leadership, persistence and determination are critical to successfully undertaking such a transformation. We have focused on senior leadership unity, service leader alignment in the field, and a thousand or so 'transformers' among our staff who are facilitating the change.

This requires us to have at the forefront of our thinking the need to progressively take the portfolio to another place where we could truly put people at the centre of everything we do. With that change, design and delivery of services should become 'outside in', with Australians telling us what they want and need - as opposed to the more traditional, internally driven 'tell you' model — and with new service offers being based on people's life events and local issues rather than the silly procedural requirements of some support programs. ${ }^{2}$

\section{What you told us: Acting on everyday Australians' feedback}

So that Australians could tell us what they wanted, the portfolio agencies conducted a series of community forums across the country to gain insight from the people who used our services. This was a first step in our commitment to develop a co-design approach and build mechanisms to more actively engage the people who use our services in designing them as well.

The forums gave us a better understanding of how people experience our services, the obstacles they face and their daily frustrations. It showed the diversity and complexity of circumstances and preferences surrounding people's use of and access to government services.

These forums also identified four common themes in people's expectations of service delivery. Firstly, people said 'make it about me'; as much as possible, they wanted services to be personalised and tailored to their individual needs at different times in their lives. Secondly, they said 'connect me where it counts'; they were looking for better coordinated services that would deliver results for them, easier and quicker access to these services, and services that are linked between different tiers of government. Thirdly, people wanted things to be 'clear

2 We are, of course, bound by the legislative and policy-driven requirements of government programs. 
and simple'; they were in search of good communication and information, simple processes and forms and intuitive online services and they wanted to deal with staff who understood and had empathy for their circumstances. And, finally, they said 'give me flexibility'. People were looking for easy and appropriate access. This did not necessarily always mean online services, although that is certainly now the preferred channel for most Australians. Some people still prefer face-to-face options, and most people prefer to talk to someone when they are dealing with sensitive or complex situations.

Naturally enough, it's when things get complex that we must really work hard to meet people's expectations. As one participant in the forums described their experience with the portfolio: '. . . if you just have general process stuff, it's good; the problem is when things fall down. If things get complicated that's when it gets bad'. This quote also highlights the fact that policy officers need to have a much clearer sense of the service delivery implications of their work, because what works logically on paper doesn't always work smoothly on the ground.

Naturally, the four themes that emerged from the forums are interdependent. These themes were the focus of the frustrations participants felt with existing service delivery as well as the bases of their suggestions for improvement. Two of the most important ideas that emerged for improvement were 'personalised service delivery', including a case management approach and 'linked up services', with the idea of a 'one-stop shop'. While these might not be radically new ideas, they do confirm that we were on track with our assumptions about people's expectations.

They also amplify how important it is for people on both sides of the counter to have an understanding of each other. For example, an Indigenous Australian participant said: '... they don't know what's going on in the outside world and we don't know what's going on in the inside. They need to come out to our communities and experience what it's like for us, to live like us and make it real for them. It should be part of their training'.

The then minister for human services, Tanya Plibersek, asserted that policy needed to begin in the real world, stating: 'getting out and seeing firsthand what is happening in communities should be an important part of your jobs as public servants'. And that is exactly the challenge that has been set for the APS through the 2010 Blueprint for Reform, which we have met by, for example, hosting ongoing forums, staff dialogues, town hall meetings in partnership with local government in Victoria, and community agency suggestions. 


\section{Citizens, customers or clients?}

On the question of whether we use the terms 'citizens', 'customers' or 'clients', I don't care much; they are all people to me, but anyone who has even a passing acquaintance with Ahead of the Game: Blueprint for reform of Australian Government administration will be aware that it is peppered with references to 'citizens'. One of the primary reforms it identifies is forging a stronger relationship with citizens through better delivery of services and through greater involvement of citizens in their government.

Whether in the market-driven models of former heads of government Ronald Reagan in the United States and Margaret Thatcher in Britain, former UK prime minister Tony Blair's 'third way' or John Howard's former government's marketdriven reforms in Australia, one phrase that seemed to gain almost universal currency in the literature and in government circles was 'customer focus'. It was a common theme that governments should adopt more of a private sector approach to dealing with their citizenry.

Governments were responding to the rising expectations of 'consumers', with a model which emphasised choice, competition, contestability and markettesting as ways of achieving efficiencies. 'Customer focus' came to be regarded as an antidote to the widely held notion that a traditional bureaucracy was characterised by red tape, inertia and rule-bound administrators providing onesize-fits-all models of service delivery.

Not everyone, however, accepted the validity of the 'customer' concept in the specific circumstances of the public sector. Many felt that it did not adequately capture the relationship between government organisations and members of the public and served, rather, to devalue the notion of citizenship. Treating the public only as customers, some thought, reduced them to passive recipients of services, rather than active participants, and ignored the fact that many people had no choice other than to deal with government.

John Alford considers 'citizens' to be those who receive 'public value' from government. ${ }^{3}$ He makes a distinction between this collective citizenry and a subset of citizens with whom an agency deals at its 'business end', and who receive 'private value'. Alford defines the latter group as 'clients', and he subcharacterises them as 'paying clients', 'beneficiaries' and 'obligatees'. The latter group might also be called unwilling clients, such as prisoners or detainees, who

3 John Alford, 'Defining the Clients in the Public Sector: A social exchange perspective', Public Administration Review, May/June 2002, volume 62, no 3. 
are the recipients of 'services' they don't necessarily want. In his view only the 'paying clients' conform to the private sector market model - one which is primarily based on economic exchange.

Searching for a broader notion of exchange that would better align with the complex relationships between government organisations and the public, Alford turned to social-exchange theory, which extends the concept of exchange beyond economic benefits to include intangible ones, such as the affirmation of social norms. As Terry Moran has put it: '... there are important elements, such as a measure of shared responsibility for the wellbeing of all in our community and the social cohesion it promotes that are not readily tradeable in a market place' $^{4}$

The social-exchange perspective asserts the importance of encouraging public servants to think about their relationships with the public in a different light - taking into account the less tangible benefits that they are able to contribute to the relationship (such as co-operation, compliance or co-production), rather than thinking only in terms of a homogenised group of recipients of transactional services, the nature of which were devised by government.

It's a perspective that highlights the fact that we serve multiple 'publics', and it can help to shape our current understanding of the respective and sometimes competing claims of these different types of citizens, and how they are interconnected. It prompts us to explore ways in which we can enhance the outcomes for one group without diminishing them for another.

The current focus should be more about the effectiveness of service delivery. For the human services portfolio, it has meant seeing ourselves a bit like the online store Amazon - a large, national delivery system within which niche products not only exist, but piggyback on the system, enabling it to flourish. That means that we need to do our core transactional government business well, and add on extra services and information in ways that are packaged to suit people's particular needs.

\section{The role of government}

The changing nature of the interaction between governments and citizens the world over has given rise to considerable theoretical debate about the role of the state in modern society. Questions in this debate include:

4 Terry Moran, 'The Quiet Revolution - Observations on public policy', IPAA Seminar (May 2005). 
- How do we raise the bar for everybody, including those with complex needs, and the majority who just want to get on with their lives and have little to do with us?

- How do we practically have both deeper and wider relationships with people in order to design better services?

For some commentators, a combination of socio-economic and political factors, such as privatisation, globalisation and the demand for governments to respond to 'wicked or intransigent problems', together with the growth of networks, has resulted in a weakening of the power and influence of governments.

According to this school of thought, government has become just one of a multiplicity of actors, and this has undermined its ability to control the policy process. This is called the 'hollowing out of the state', denoting a shift away from the traditional, centralised focus of government to more of a societycentred perspective. There is even discussion of the emergence of 'governance without government'.

Others argue that this society-centred perspective is overstated or flawed. Stephen Bell and Andrew Hindmoor take the view that, although governments are now demonstrably more likely to forge relationships with a larger range of non-state actors, they nevertheless remain the central players in governance arrangements. ${ }^{5}$ Indeed, they argue that governments have been strengthened through the relationships that they have developed.

Whatever position one takes, a confrontational question flowing from this debate is whether genuine citizen or people-centred approaches can happen 'in the system'. In other words, can the public sector be the agent to develop the sort of community capacity required for real change, or does it need to step aside sometimes?

\section{Evolution of service delivery reform in Australia}

At this point, it is useful to remind ourselves that the push for services that are more responsive to the needs of citizens is not a new development. 'Citizencentred' may have become a buzz word in the past decade, but the concept it embodies has a long history.

When a 1976 government inquiry (the Coombs Royal Commission into Australian Government Administration) reported on the need for public sector reform, a major concern was that the public service was less responsive to

5 Stephen Bell and Andrew Hindmoor, Rethinking Governance: The centrality of the state in modern society, Cambridge University Press, 2009. 
changing community needs than it should have been. This led to a number of important changes in public administration, including more responsive service delivery. The past 30 years or so has seen a continuing trend away from a rigid, entitlement-based service delivery model to more flexible, place-based and individually tailored approaches.

Indeed, the 'simple but powerful idea' behind the creation of Centrelink in 1997 was: '. . to make it easier for citizens to do business with the government, as opposed to pursing a mode of operations convenient for those delivering the service'. ${ }^{6}$ The question, though, is whether progress in this evolutionary process has been rapid enough in recent years. We have been calling for new approaches for quite some time now.

While I am extremely proud of what has been happening in the portfolio I left in mid-2011, I am not sure that the public service as a whole has proceeded into that new era as quickly as I might have liked. It is very easy for public servants to keep on doing things the way they always have, rather than to think and behave differently. I am constantly struck by the view that, rather than embrace change, people want to be resourced to deliver something different. Transformation requires not only structural change, but behavioural and cultural change. It's time to push on even more rapidly with implementing this new paradigm. The community is impatient for change and the Internet and almost daily new information technologies provide the potential for transforming our institutions very rapidly. ${ }^{7}$

\section{International context}

Our service delivery reforms are, of course, part of the ongoing evolution of public administration in general. Given we now operate in a global environment, it's logical that the reforms we are experiencing in the APS are echoed in other developed nations around the world, as well as in other Australian jurisdictions.

Last year, Canadian academic Kenneth Kernaghan undertook a comparative study of international innovations in service delivery. ${ }^{8}$ He observed that the international exchange of good practices in service delivery has had a major impact on service improvement initiatives around the world. For example, New Zealand's Kiwis Count, a national survey of citizen satisfaction with public services, is adapted under license from Canada's Citizens First surveys.

6 Australian Government (Management Advisory Committee), Connecting Across Boundaries - Making the whole of government agenda work, Commonwealth of Australia, Canberra, November 2010.

7 They also intensify the pressure for government to perform at the 'speed of the Internet.'

8 Kenneth Kernighan, International Innovations in Public Sector External Service Delivery, Treasury Board of Canada, March 2010. 
He also pointed to Malaysia's use of mobile devices for service delivery and the open government initiatives of the United Kingdom and the United States as developments that could easily transfer to Canada. In Australia we are also looking for inspiration in what is happening in other countries. Indeed, the new Local Connections to Work program, which was recently introduced through a DEEWR/DHS partnership, ${ }^{9}$ is based on a model that began in New Zealand a few years ago.

Canada has merged many of its government shopfronts and integrated phone numbers and websites to provide customers with themed information based on life events, such as 'finding a job' and 'raising a family' initiatives. In Australia, we have considered similar approaches and are co-locating many of our frequently used offices so that people can access more services in one location.

Through this joining-up, we are also expanding access to services to those in rural and regional areas who might previously have had to travel hundreds of kilometres to their nearest Medicare office. We are also expanding some of our own successful innovations, like mobile offices that are deployed quickly in emergency situations.

\section{Are we doing enough?}

Government in Australia is making clear progress in moving towards citizencentred services, but the challenge is that expectations of government are growing at an even faster rate. At the time I stepped down as CEO of Medicare Australia in July 2012, some 34 Medicare Australia and Centrelink offices were offering integrated services, and a single phone number and single website for the portfolio had been launched. By the end of 2014, the intention is for around 570 offices to be providing integrated services.

Initiatives to allow people to take action themselves are also being pursued. Increasing numbers of transactions can be completed on line; for example, electronic claiming of Medicare rebates has recently been introduced, and existing online customers can now use a single login for all the human service portfolio's services. Over time, many more self-service options will be introduced to ensure better, more consistent service through all access channels and, better still, we will do most of the work behind the scenes.

9 The partnership between the Department of Employment, Education and Workplace Relations and the Department of Human Services. 
New forms of dialogue with service users, the community, providers and intermediaries will help to reality-test whether what is being done is what people want to see happening. This is the very different and necessary perspective the Department of Human Services is taking to deliver twenty-first century service.

\section{What does citizen-centred service look like?}

Discussion of big reform initiatives can be pitched at a lofty level, but, in the end, it all comes down to making things better for people. Hearing people's stories and thinking about what can be done to improve their lives in a practical sense helps us to take a reality check on the goal to be achieved.

Take the situation of a family learning that their child has a disability. Their immediate priorities are usually about getting help for their child. The parents may or may not know where to turn first, and this is where a linked-up approach will come into play. And, while the Australian Government won't deliver all of the programs that parents may require, they will have ideas about who does and, consequently, should be able to link the parents to the relevant sources of help at the local level, particularly as the child moves through school.

While the parents are focusing on the needs of their child, government can help to ensure that their personal needs are met too, such as through coordinated and streamlined access to income support or ancillary payments, Medicare rebates, referrals to respite services or other programs to increase their wellbeing. By thinking and acting to address the needs of the entire family, the government can help protect them from the financial and personal pressures that can so easily impact on their relationships and health. This sort of preventive and caring service is what true citizen-centred service is about.

This example shows what an 'outside in' approach can mean for people and how collaborative schemes involving government working together with people and service professionals and the 'not-for-profit' or 'third sector' can improve public service delivery in ways that rigid program structures fail to do. By integrating sources of information around life events or local services, and providing things like 'warm' transfers (inter-agency/program facilitations) to other services for those with multiple, complex problems, overall wellbeing is improved.

To support this approach, we are moving to embed co-design principles in our operations. In simple terms, co-design is a systematic approach to understanding our customers and working with them to design, shape and deliver better services. Co-design is about the transfer of power from provider to user. Transferring power involves a shift in obligations and responsibilities, 
something that has to be negotiated between the government and the person receiving the service. To manage that shift properly, we need to understand the people we assist; we need to see the world and their lives just as they see them.

It follows that, if service quality and effectiveness is to be improved in ways that focus on the citizen, then citizens also have obligations. This extends not only to complying with rules, but also to people changing their behaviour and accepting responsibility for the choices they make, including the bad ones.

This approach is reflected in Australian social inclusion policies in which one of the principles is a greater voice, combined with greater responsibility, which is further articulated when people feel that they have a responsibility, indeed an obligation, to take part and to make progress. We need to work with people to design a government system that will ensure citizens are motivated to take responsibility.

A shift away from the control culture within government is also required. Control is anathema to the creativity and innovation needed from public servants to get true transformation. We obviously need to work within the law and the parameters set by the government, but, at the same time, we also need the room to create real, local solutions.

Importantly, public servants will also have to accept that they don't always know best - or even, don't know at all and so should go out and actively seek ideas and input. Most importantly, they need to take time to make sure that they are asking the right questions. We can identify a virtuous circle here: co-design should enable us to offer better quality services, which in turn will generate better user experiences with those services. Through co-design techniques, we can then use these experiences to further improve quality, and repeat the cycle.

This virtuous circle will also help to influence policy, build trust in government and overcome some of the reluctance that certain individuals and groups in the community feel towards engaging with government agencies. If people can see that public servants are genuinely listening to their views and acting on what they say, they will be more inclined to take up opportunities for participation. They will also see that their ideas matter.

So, too, do policy advisers need to begin to engage actively with service delivery staff and the citizens using these services. This already happens, but not nearly often enough. Wouldn't it be grand to have the work of public service policymakers and service deliverers or program managers fully integrated around the needs of citizens, rather than separated and disconnected, as is the case now? Getting feedback loops working well and being bold enough to invite service users into our design processes is fundamental to delivering citizen-centred services. The public service could and should be doing this much better. 


\section{Where to now?}

To this end, I think it is important that a more analytical approach to service delivery is applied. Specifically, there needs to be:

- a greater focus on systems thinking and collaborative policy and program design; as part of this, we need to understand the overall impact of complexity and the fragmentation of services and related requirements on citizens

- use of communities of interest across public service agencies involved in service delivery, focusing on the intersections, how to better join up services, and sharing innovative approaches

- more sophisticated data to build a picture of what matters to people

- the active use of evaluation and prototyping to test different approaches to engagement and service coordination so that we have a more informed understanding of what works and what doesn't

- greater mobility between the public service and the community sector as a way of increasing mutual understanding.

If these steps are taken there will be scope to ensure change keeps happening. Co-design is interactive and, in time, it also becomes transformative as the sea of initiatives crystallise into major change.

\section{Conclusion}

In conclusion, while there are significant challenges ahead, there is a real appetite across the public service to tackle the challenge of shifting to more citizen-centric delivery. If we look at the results of the annual state of the service employee survey, it is clear that the majority of Australian Government employees are keen to be creative and innovative, and work collaboratively across boundaries to deliver quality outcomes for the people that they serve. They are sometimes frustrated by the systemic constraints they experience, but my sense is that they are champing at the bit to take justifiable risks and try out new approaches. I'm excited about the direction in which the public service is moving and very optimistic about its future. 